\title{
OS VALORES PRAGMÁTICO, AFETIVO E SIMBÓLICO NO PROCESSO DE MEDIAÇÃO CONSCIENTE DA INFORMAÇÃO
}

\author{
THE PRAGMATIC, AFFECTIVE AND SYMBOLIC \\ VALUES IN THE PROCESS OF CONSCIOUS \\ MEDIATION OF INFORMATION
}

\author{
Raquel do Rosário Santosa \\ Ana Claudia Medeiros de Sousa ${ }^{b}$ \\ Oswaldo Francisco de Almeida Júniorc
}

\begin{abstract}
RESUMO
Introdução: O processo de mediação consciente da informação é evocado e necessário para garantir a apropriação da informação em consonância com o contexto sociocultural em que as relações entre os sujeitos, os mediadores e os ambientes informacionais estão inseridos. Nessa conjuntura, é preciso compreender os diferentes valores pragmático, afetivo e simbólico - que permeiam o processo de mediação da informação, que estão refletidos e refletem as tessituras constitutivas das teias sociais. Objetivo: Discutir, com base na fundamentação teórica da mediação da informação, sobre os valores pragmático, afetivo e simbólico que permeiam o processo consciente de mediação e o tornam humanizador. Metodologia: Trata-se de uma pesquisa descritiva, de natureza qualitativa. No que se refere aos procedimentos, caracteriza-se como bibliográfica. Resultados: Quando os usuários e o próprio mediador compreendem a ação mediadora deste último agente como uma concepção de vida, favorecem o desenvolvimento de uma convicção da relevância e da responsabilidade social de suas ações. Conclusões: A pesquisa propõe que, no processo de mediação consciente da informação, sejam atribuídos os valores pragmático, afetivo e simbólico à ação mediadora tanto pelos usuários quanto pelo próprio mediador, o qual a relaciona a uma atuação humanizada e favorece o desenvolvimento de uma convicção da relevância e da responsabilidade social de suas ações.
\end{abstract}

Descritores: Mediação da informação. Valor pragmático - Mediação da informação.

\footnotetext{
a Doutora em Ciência da Informação pela Universidade Federal da Paraíba (UFPB). Docente do Departamento Documentação e Informação da Universidade Federal da Bahia (UFBA). E-mail: quelrosario@gmail.com

b Doutora em Ciência da Informação pela Universidade Federal da Paraíba (UFPB). Docente do Departamento Documentação e Informação da Universidade Federal da Bahia (UFBA). E-mail: ana.violista@gmail.com

c Doutor em Ciências da Comunicação pela Universidade de São Paulo (USP). Docente do Programa de Pós-Graduação em Ciência da Informação da Universidade Estadual Paulista (PPGCI-UNESP). E-mail: ofaj@ofaj.com.br
} 
Valor afetivo - Mediação da informação. Valor simbólico - Mediação da informação.

\section{INTRODUÇÃO}

A mediação da informação vem sendo refletida como um processo de interferência que visa à apropriação da informação, gera novas necessidades informacionais nos sujeitos e causa conflitos informacionais (ALMEIDA JÚNIOR, 2015). Partindo desse pensamento, entendemos que, quando essa ação é realizada conscientemente, alcança dimensões que, segundo Gomes (2014, 2016, 2017), tornam-na significativa para transformar a realidade de mediadores e de usuários da informação e contribuem para o surgimento de novos protagonistas sociais. Oliveira (2014) defende que é necessária a negociação, que ocorre entre mediadores e usuários para que a mediação da informação contemple os anseios desses agentes. Nesse processo, é preciso considerar, ainda, que é sobremaneira importante reconhecer os valores pragmático, afetivo e simbólico atribuídos pelos profissionais da informação às ações mediadoras, que poderão reconhecer a importância de uma atuação humanizadora no processo de mediação da informação, tornando o seu fazer uma concepção de vida. Esse traço identitário pode ser reconhecido pelo usuário.

A mediação envolve pessoas e traz, sempre, uma relação conflituosa, de interesses e embasada em acervos de conhecimentos e de experiências diferentes. Há que se ressaltar que a mediação envolve, necessariamente, um "terceiro", que pode ser algo material, tangível. Apesar disso, a construção desse material é sempre realizada por um sujeito, que aponta para a existência de "terceiros" na mediação.

Os estudos sobre a mediação da informação possibilitam analisá-la sob vários aspectos e entendê-la com foco em alguns parâmetros. Entre eles, destacamos a mediação consciente e a inconsciente, porquanto todo ser humano se apropria da informação por meio de um processo de mediação consciente e de ações inconscientes. Entretanto, busca-se uma mediação que apoie, de maneira sistemática e crítica, todo o processo de relação entre os sujeitos e a informação. 
Nessa conjuntura, não se pode negar a existência de sistemas em que os processos informacionais são manipulados e controlados. Em igual medida, nossa criticidade é burlada por formas de envolver, de veicular e de escamotear interesses. As informações sub-reptícias estão presentes em vários dispositivos disseminadores. Alguns autores, entre eles, Philipe Breton (1999), estudam a manipulação da palavra e os artifícios empregados para nos levar a aceitar o que está por trás da informação. Emprega-se, por exemplo, uma linguagem infantilizada, um apelo sentimental forte etc., sempre buscando romper nossa barreira crítica. Vale incluir aqui as fake-news (termo já disseminado, mas que preferimos utilizar "informação enganosa"), a desinformação, a contrainformação, que sempre estiveram presentes na história da informação, mas, devido a uma série de circunstâncias, hoje fazem parte das principais preocupações dos pesquisadores da área. Assim, é latente a necessidade de mediadores que atuem de maneira consciente e entendam o cenário em que os sujeitos estão inseridos e suas necessidades distintas no processo singular de apropriação da informação.

Esta comunicação teve o objetivo de discutir, com base na fundamentação teórica da mediação da informação, sobre os valores pragmático, afetivo e simbólico que permeiam o processo consciente de mediação e o tornam humanizador. Para isso, a pesquisa buscou refletir e discutir sobre elementos presentes nos estudos de Almeida Júnior (2015); Gomes $(2014,2016,2017)$ e Oliveira (2014), que fundamentaram as concepções construídas e apresentadas nesta comunicação.

Quanto ao delineamento metodológico, esta pesquisa é descritiva, de natureza qualitativa. De acordo com Gil (2010, p. 27), a pesquisa qualitativa tem "[...] o objetivo de descrever as características de determinada população ou fenômeno ou, então, de estabelecer relações entre variáveis." Assim, esta pesquisa visa descrever os aspectos basilares da mediação da informação que são discutidos na literatura científica da Ciência da Informação. No que se refere aos procedimentos, trata-se de uma pesquisa bibliográfica que, para Gil (2010), é realizada com base em textos científicos. A pesquisa em tela não visa fazer um levantamento quantitativo dos textos que tratam sobre a mediação da 
informação, ela busca, por meio de estudos reconhecidos pela comunidade, retomar a discussão sobre os elementos norteadores do processo mediador que podem apoiar o avanço de reflexões sobre o tema em questão.

Como resultado, a pesquisa propõe que, no processo de mediação consciente da informação, sejam atribuídos os valores pragmático, afetivo e simbólico às ações mediadoras tanto pelos usuários quanto pelo próprio mediador, que o relaciona a uma atuação humanizada e favorece 0 desenvolvimento de uma conviç̧ão da relevância e da responsabilidade social de suas ações que é propulsora e constituinte do seu próprio ser social, portanto, uma concepção de vida.

\section{ATRIBUIÇÕES DOS VALORES PRAGMÁTICO, AFETIVO E SIMBÓLICO NO PROCESSO DE MEDIAÇÃO DA INFORMAÇÃO CONSCIENTE E HUMANIZADORA}

O processo de mediação da informação ocorre na relação entre o profissional da informação e o usuário nos (e com os) dispositivos socioculturais, portanto, é no agir que os sujeitos, os meios e os dispositivos atribuem e ganham significado mediador. Em alguns casos, principalmente quando ainda não se tem um parâmetro teórico e metodológico, tanto o profissional da informação quanto o usuário não tomam consciência do valor de suas atuações no processo de mediação da informação. Quando essa mediação inconsciente é feita em um contínuo, uma falta de sistematização e de consciência repercute, principalmente, no fazer do mediador, que atua sem perceber as dimensões que deve alcançar nesse processo, e isso ocasiona uma falta de atribuição de sentido também pelo usuário. Como já dissemos, a mediação inconsciente da informação ocorre apesar de contrária aos desejos e às vontades dos sujeitos que se relacionam com ela. No entanto, podemos e devemos buscar formas de amenizar essa impossibilidade de domínio, como, por exemplo, a competência em informação e a busca por compreender os mecanismos empregados para romper nossas barreiras críticas.

Em uma ação de mediação consciente, também pode haver pequenos 
lapsos de inconsciência, quando uma nova demanda do usuário eleva o nível da proposta do mediador, mas, rapidamente, ele e o usuário interagem e percebem os meios, os objetivos e as metas a serem atingidos.

É no âmbito da tomada de consciência que se discute sobre o fazer dos agentes no processo de mediação da informação, não apenas pelo mediador da informação, mas também pelo usuário, que passa a atribuir valor a esse processo. O profissional da informação precisa entender a responsabilidade das ações mediadoras para com o outro e perceber que esse agir vai além dos espaços de atuação profissional. É nessa ação, que se prolonga entre os espaços sociais, que o profissional da informação se reconhece como mediador e atuará em consonância com os sentimentos, as percepções e as necessidades do usuário, que identificará a relevância da mediação para cumprir seu papel social. Assim, no reconhecimento do usuário e no valor atribuído por ele, o profissional da informação também reconhece o valor de existir e de atuar no processo de mediação da informação. Isso contribui para que sua atuação não seja apenas profissional, mas também uma concepção de vida imbuída de convicção da relevância do seu papel nos contextos socioculturais.

Convém enfatizar que, quando o mediador e o usuário se envolvem consciente e inteiramente no processo de mediação da informação, alcançam o potencial sensorial ao evocar emoções e ressignificar o sentimento de pertencimento. Nesse sentido, a percepção sensorial relaciona-se com a escuta, com a fala, com o gesto e com o olhar sensível do sujeito com seu meio no processo de mediação da informação. A percepção sensorial evoca as lembranças, as vivências e as entidades afetivas que o sujeito constitui em suas relações sociais. Assim, o mediador da informação deve ter uma postura consciente em relação a essa percepção sensorial, porque essa ação favorece a interferência humanizadora.

Os elementos discutidos acima sobre a mediação inconsciente e a consciente da informação são apresentados e refletidos por Almeida Júnior (2015, p. 25), que compreende a mediação da informação como

[...] toda ação de interferência - realizada em um processo, por um profissional da informação e na ambiência de equipamentos informacionais -, direta ou indireta; consciente ou inconsciente; 
singular ou plural; individual ou coletiva; visando a apropriação de informação que satisfaça, parcialmente e de maneira momentânea, uma necessidade informacional, gerando conflitos e novas necessidades informacionais.

Percebemos que esse conceito demonstra as distintas formas como 0 mediador exerce seu fazer, o objetivo com o qual age e o resultado que espera alcançar. Entretanto, o sujeito que está vinculado ao processo de mediação - o usuário - também interfere e não só se apropria da informação, como também de todo o processo mediador. Quando o profissional da informação e o usuário atuam na mediação da informação, esse conceito pode ser compreendido como um processo cíclico, pois os agentes interferem na informação e no próprio processo mediador, que agrega a posição que os sujeitos ocupam e os dispositivos que são adotados, e lhes atribuem sentido. Assim, a mediação da informação também é apropriada, porque passa a ser percebida, compreendida e exercida de maneira consciente e (re)significada, o que demanda novas necessidades informacionais e de mediação.

Considerando o exposto, defendemos que a mediação da informação não se limita ao agir do profissional da informação, porque também envolve as atribuições que o usuário exerce nesse processo e the confere. Os profissionais da informação, além de auxiliar no acesso e no uso da informação, devem apoiar o sujeito em sua (trans)formação, no desenvolvimento de competências em informação e também se (trans)formar, pois a interferência ocorre de maneira mútua, que repercutem na vida do usuário e do mediador, como também do contexto sociocultural em que eles estão inseridos.

Sabendo que a mediação ocorre em outras áreas do conhecimento, como na Religião, no Direito, na Educação, na Medicina, entre outras, é preciso observar que seus agentes mediadores, mesmo em cenários sociais que não o do exercício profissional, são reconhecidos e revestidos de suas aptidões profissionais. Nesse sentido, o arquivista, o bibliotecário e o museólogo devem se reconhecer, atribuir sentido ao seu papel social como mediadores e possibilitar percepções sensoriais sobre ele, porque a mediação da informação pode ser reconhecida no âmbito dos dispositivos informacionais e gera sentido e significado no modo como o mediador age no mundo, das interferências que 
realiza e no retorno que obtém do usuário diante da consciência de sua responsabilidade social. Assim, para além dos dispositivos informacionais, o mediador da informação também atua nos dispositivos sociais e culturais, portanto, deve deixar claro seu papel social.

Vale ressaltar que um mesmo dispositivo pode ter o significado social, informacional e cultural, entretanto, só terá esse reconhecimento se os sujeitos tiverem conscientes disso. $O$ termo dispositivo é adotado nesta pesquisa sob o ponto de vista de Pieruccini (2007), que o entende como

[...] um signo, um mecanismo de intervenção sobre o real, que atua por meio de formas de organização estruturada, utilizandose de recursos materiais, tecnológicos, simbólicos e relacionais, que atingem os comportamentos e as condutas afetivas, cognitivas e comunicativas dos indivíduos.

A partir desse entendimento, podemos exemplificar que uma biblioteca opera no sentido informacional, mas, se os sujeitos - mediador e usuário ampliarem suas percepções, poderão reconhecê-la como um dispositivo constituído pelas necessidades e demandas sociais e carregado de valor identitário e memorialístico, ou seja, atribuindo-lhe um valor simbólico.

Quando o profissional da informação compreende o seu agir para além do âmbito profissional e atribui à mediação da informação uma convicção de agir no mundo, um modus operandi poderá contribuir para que os sujeitos possam compartilhar conhecimentos e aspectos ligados à cultura, aos saberes e às crenças de grupos sociais, (re)conhecer os ambientes informacionais como dispositivos socioculturais, em que podem se empoderar, compreender a história de vida do outro, reconhecer suas diferenças e respeitá-las e interagir com eles.

Nesse ponto, é importante ressaltar que, segundo Almeida Júnior (2015), as ações de mediação da informação ocorrem de maneira singular e/ou plural, porquanto o mediador deve entender que cada sujeito tem sua singularidade, que o torna diferente em seus múltiplos aspectos, seja por causa de seu conhecimento, da história de vida, do comportamento e da relação que estabelece com outros sujeitos e com o contexto sociocultural. Essas ações também se manifestam de maneira individual ou coletiva, porque o mediador auxilia o usuário a se apropriar da informação e the possibilita uma mudança interna e externa, por meio de suas ações diretas e indiretas de mediação da 
informação.

Quando a mediação da informação contempla uma interferência dos usuários, eles passam a se reconhecer como constituintes de um conhecimento e uma história de vida que são singulares e atuam no processo de compartilhamento coletivo. O mediador da informação age com os usuários de maneira que, em ações coletivas e plurais, eles se reconheçam e atuem com sua singularidade e individualidade. Ambos podem atingir o protagonismo social.

Quando o agente mediador e os usuários ocupam o mesmo nível de importância no processo de comunicação, o diálogo e a troca de conhecimentos ocorrem de maneira fluida, como uma ação compartilhada e colaborativa. Gomes (2014, 2016, 2017) compreende que, ao alcançar a dimensão dialógica, os sujeitos adquirem a consciência de propiciar e se apropriar dos espaços de interação.

Os sujeitos da ação comunicativa precisam transitar com 'conforto' no 'ambiente' do encontro, no espaço da interlocução, precisam desenvolver o sentimento de pertença, já que o encontro promissor com a informação é aquele capaz de gerar o terreno propício para o desenvolvimento intelectual e a construção do conhecimento. E esse 'conforto' se consolida a partir de uma base comunicacional dialógica, por meio da qual as ideias podem transitar sem censura ou rejeição e os debates sejam decorrentes do exercício da crítica e dependentes da interação paritária dos participantes da ação (GOMES, 2014, p. $50)$.

Esse "sentimento de pertença" que Gomes (2014) indica confere desejo e prazer ao mediador e ao usuário que vivenciam e realizam as ações de mediação da informação e alcançam a dimensão estética.

Ainda de acordo com Gomes (2016), a dimensão formativa se caracteriza pelo surgimento e aprimoramento de novas competências do mediador e do usuário, que podem estar implícitas no processo de mediação da informação, como, por exemplo, a escuta sensível e o acolhimento, elementos essenciais nesse processo. Quanto à dimensão ética, permeia as atividades de mediação e evita a manipulação e a exclusão social, para que a apropriação da informação ocorra por meio da interferência consciente e competente do mediador. Nessa conjuntura, ao tomar consciência de sua condição de protagonista social, o mediador da informação passa a atuar na perspectiva da 
dimensão política, "[...] a potência transformadora que pode decorrer da ação mediadora [...] que vindica do agente mediador uma tomada de posição acerca do papel social." (GOMES, 2016, p. 101).

Protagonistas assumem ações de liderança, se colocam contra obstáculos que representem ameaça ao coletivo, assumem embates pela construção de um mundo em favor do bem comum. Ser protagonista implica na tomada de posição de sujeito social ativo, que age e reage com e em relação ao outro (presente ou não na cena da ação). Enfim, o protagonista é aquele que age, que reage, que se ergue, que se coloca em relação aos interesses do coletivo. (GOMES, 2019)

Até em uma ação consciente de mediação da informação, os mediadores podem se deparar com barreiras impostas pelos aspectos geográficos, ambientais, culturais, políticos e econômicos. Entretanto, ao assumir sua posição como protagonistas sociais, atuarão de maneira proativa no combate e no enfrentamento dessas barreiras, cujos fatores os impulsionam a encontrar formas de transformar sua realidade e a dos sujeitos e de contribuir para o surgimento de novos protagonistas sociais.

Nessa perspectiva, a mediação da informação é consequência do alcance das cinco dimensões defendidas por Gomes (2014, 2016, 2017), a saber: a dialógica, a estética, a formativa, a ética e a política. Quando as cinco dimensões são alcançadas de maneira articulada, a ação mediadora contribui com a apropriação da informação, por meio da qual o protagonismo social se desenvolve.

Nesse momento, é preciso recordar que o processo de mediação da informação envolve o usuário, o mediador, o dispositivo informacional, como apresentado, além de outros personagens e fatores, como o produtor da informação; as formas de armazenar e de organizar; os serviços prestados; os acessos a acervos; as políticas públicas de informação, educação e cultura; os olhares e o entendimento de mundo por parte de todos os participantes; o ambiente do dispositivo informacional e as condições no momento da mediação; a comunidade em que vivem os usuários; as diferenças de vida entre mediadores e usuários etc. Esses personagens e fatores alteram a mediação e a tornam única.

Há que se ressaltar que, a mediação, mesmo depois de seu final formal, 
não termina, continua latente e reverberando no mediador e no usuário. Cada uma das mediações implica mudanças nesses personagens e no próprio dispositivo informacional. A mediação é momentânea, mas perene, embora isso possa, aparentemente, ser uma contradição. A construção do nosso conhecimento só é possível na nossa relação com os outros e com o mundo.

Reiteramos que a busca pela mediação consciente da informação está atrelada a um olhar e a uma escuta sensíveis, à abertura do espaço de fala e ao acolhimento ao outro, o que resulta em um agir humanizador, em que os sujeitos são considerados como fundamentais em seus múltiplos anseios, papéis sociais e diversas necessidades que os tornam sujeitos moventes. Para responder às demandas e seus papéis como atores sociais, os sujeitos buscam, nos dispositivos informacionais, respostas para esses anseios. Assim, a primeira demanda ou a mais recorrente que o mediador e o usuário visam suprir é a pragmática. É possível considerar que o sujeito e o mediador atribuirão valor ao processo de mediação da informação por responder às necessidades informacionais. Esse é um valor pragmático.

As necessidades, os interesses e os desejos dos usuários não são puros, porque estão imersos em um contexto, em um sistema que Ihes impõe muitas necessidades "desnecessárias", que só atendem à sobrevivência deles produção e consumo de mercadorias, acúmulo de capital, por exemplo. Os dispositivos informacionais atendem às demandas, porém também criam demandas e tentam, dentro do possível, evidenciar essas necessidades impostas. O valor pragmático lida com esse problema e também o considera.

Ao se apropriar da informação e dos dispositivos informacionais, o usuário poderá entender que a mediação da informação não responde apenas a uma demanda imediata ou apresentada por suas atividades sociais e passa a reconhecer a beleza e o prazer das ações mediadoras da informação, como defende Gomes $(2014,2016,2017)$, quando trata da dimensão estética. É por meio do fortalecimento dos laços entre o mediador e o usuário e da ambiência gerada pelos dispositivos informacionais que esses sujeitos passam a atribuir o valor afetivo ao processo de mediação da informação, por perceber que esse também é um processo que o constitui como ser social. A Academia parece 
desconsiderar tudo o que não seja racional. Defendemos - e nos parece já ter ficado evidente - que razão e sentimento se imbricam e formam um amálgama indissociável. Todo fazer do profissional da informação, em especial, no âmbito da mediação da informação, implica ações que envolvem a razão e o sentimento.

Os arquivos, as bibliotecas e os museus, como também seus agentes mediadores, podem integrar alguma lembrança afetiva que, em dado momento da vida, os sujeitos experienciaram. Esses ambientes informacionais podem disponibilizar dispositivos como cartas, fotografias, músicas, livros, revistas etc., que guardam traços identitários dos indivíduos e dos grupos que evocam uma percepção sensorial, além de agregar o valor afetivo. Quando a identidade individual também tem uma dimensão coletiva e constitui os traços memorialísticos de grupos sociais, é possível que, além do valor afetivo, seja atribuído o valor simbólico, porque a sociedade reconhece o pertencimento dos dispositivos informacionais que transparecem fatos, acontecimentos e histórias de vida de sujeitos e grupos sociais.

Essa realidade, em que os dispositivos informacionais integram a história de vida dos sujeitos, nem sempre é alcançada, posto que muitos encontram diversas barreiras sociais, econômicas, políticas etc. que os impedem de reconhecer o arquivo, a biblioteca e o museu como ambientes que devem ser apropriados por eles. Entretanto, nesse terreno árido, o mediador da informação não pode desanimar ou recuar, mas deve atuar como protagonista social e demonstrar que os dispositivos informacionais são ambientes coletivos e pertencentes aos distintos grupos formadores da sociedade. Assim, é preciso realizar constantemente um processo de negociação, para que seja possível identificar, nos dispositivos informacionais, aspectos que façam sentido aos diferentes sujeitos sociais.

A mediação consciente da informação também contribui para que o agente mediador alcance seus objetivos ao "negociar" (OLIVEIRA, 2014) com indivíduos e grupos sociais, a fim de que eles se apropriem dos dispositivos informacionais. Para que esse processo seja efetivo, o mediador e os usuários devem interagir e apresentar suas realidades e possíveis caminhos a serem 
traçados na busca por respostas. Para isso, é necessário saber negociar diante das situações.

A negociação contempla, além de um modo de se relacionar, a busca por um diálogo (mesmo se árduo) na situação de divergência, ou seja, existe a consideração do outro enquanto possibilidade de troca e mudanças (dele e do 'si mesmo'). Não é, portanto, ruptura, nem imposição pela força, como no caso da guerra, mas possibilidade jogada no âmbito de disputas que se valem da capacidade humana de simbolizar e de expressar-se por meio da linguagem (OLIVEIRA, 2014, p. 114).

Esse processo de negociação, que fundamenta a mediação da informação, deve ser pautado no reconhecimento dos elementos identitários e socioculturais que conferem sentido e significado aos sujeitos. $O$ reconhecimento dos elementos socioculturais pode ser considerado um parâmetro para a negociação. Isso requer do mediador da informação a consciência de que suas ações podem ser influenciadas pelos sujeitos, ou seja, o mediador deve atuar de maneira a possibilitar que os traços identitários dos usuários sejam contemplados nesse processo.

Ao negociar os sentidos e fortalecer a comunicabilidade e a interação entre os sujeitos, o agente mediador deve promover ações que tornem conhecidos os bens culturais, considerando as especificidades dos espaços sociais para viabilizar a apropriação da informação e fortalecer a memória e a identidade de indivíduos e grupos sociais. Pollak (1992, p. 5) compreende a memória como "[...] um elemento constituinte do sentimento de identidade, tanto individual como coletiva, na medida em que ela é também um fator extremamente importante do sentimento de continuidade e de coerência de uma pessoa ou de um grupo em sua reconstrução de si." Nesse contexto, a produção da informação expressa construções identitárias, descortina traços de memória e é capaz de revelar a estrutura sociocultural de quem a produziu, o que contribui para que os usuários e os mediadores atribuam valor simbólico ao processo de mediação da informação.

Esse valor simbólico, que é identificado quando a mediação consciente da informação se inter-relaciona com os aspectos socioculturais, evidencia os vestígios identitários e memorialísticos dos dispositivos informacionais e dos grupos sociais e possibilita que os sujeitos vinculados a determinado espaço 
sociocultural e de outros que perpassam as fronteiras geográficas (re)signifiquem elementos. Nesse sentido, os agentes mediadores da informação devem estar atentos em suas atribuições e considerar a relevância dos bens culturais tangíveis e intangíveis que permeiam a esfera sociocultural, adotando uma percepção sensorial humanizadora, que aproxime os sujeitos sociais e reconheça seus traços identitários e memorialísticos nos dispositivos informacionais.

O usuário traz para a mediação seu acervo de conhecimentos e de experiências que vivem integrados. A experiência se baseia na relação do sujeito com o mundo e inclui o simbólico. Essa relação espelha o olhar do outro e que se vale de outros olhares. Juntamos olhares de outros com nossos olhares e incluímos nossa vivência, nossas interferências no mundo. É preciso deixar claro que textos escritos também nos apresentam olhares, assim como imagens e sons (incluindo a observação dos outros e a oralidade). Tudo isso nos possibilita estar e nos posicionar no mundo. O simbólico também pode ser imposto - e o é - e pode ser manipulado - e o é. No entanto, em relação à apropriação da informação, devemos procurar formas de amenizar os problemas que temos para compreender, entender e perceber essas manipulações.

A partir da consciência dos elementos que integram o conceito de mediação da informação (ALMEIDA JÚNIOR, 2015), do alcance das dimensões dialógica, estética, formativa, ética e política apontadas por Gomes (2014, 2016, 2017) e da concepção defendida neste texto sobre o reconhecimento por parte dos usuários e dos mediadores dos valores pragmático, afetivo e simbólico que permeiam o processo de mediação da informação, poderão fundamentar tanto a apropriação da informação quanto dos dispositivos informacionais, que favorecerão o agir protagonista.

Por meio das percepções e das atribuições dos valores pragmático, afetivo e simbólico, no processo de mediação consciente da informação, os usuários e o próprio mediador relacionam a atuação deste último agente - o mediador - à compreensão de sua ação mediadora como uma concepção de vida, que favorece o desenvolvimento de uma convicção sobre a relevância e a responsabilidade social de suas ações que é propulsora e constituinte do seu 
próprio ser social.

Na perspectiva da responsabilidade social do mediador da informação, é preciso que ele reflita sobre os meios em que suas ações de interferência, que possibilitam a aproximação e a relação entre o usuário e a informação, sejam desenvolvidas, buscando, de maneira consciente, proporcionar uma relação crítica, para que a mediação favoreça não só uma utilização imediata, visando responder a uma demanda prática, mas também uma relação simbólica em que a informação possa ser (re)significada.

Gomes (2016, p. 101), ao tratar da comunicação e da informação, afirma que "[...] o encontro promissor com a informação é aquele capaz de gerar o terreno para o desenvolvimento cultural, intelectual e da construção do conhecimento." Para alcançar tal objetivo, a autora indica que é necessário o "conforto", que se consolida em uma base comunicacional dialógica, em que as ideias transitam sem censura ou rejeição. Com base no exposto, podemos afirmar que, além do "conforto", que possibilita o encontro entre o sujeito e a informação, também se defende a necessidade de considerar o tempo coletivo e o individual em que se constitui esse "encontro".

As relações construídas pelos sujeitos, seja entre eles ou na experiência com algum elemento que subsidia a ação social, como a informação, não são naturais, súbitas ou acidentais, pois existem fatores preponderantes que consolidam as relações humanas. Um deles é o tempo.

O tempo individual de aprendizagem, que é o destinado à pausa, ao silenciamento, ao momento de interação, de comunicação e de debate, entre outros singularmente adotados para criar a informação e se apropriar dela não pode ser uniforme. A apropriação da informação tem diferentes tempos. Os mediadores da informação e da cultura, assim como os demais sujeitos, devem considerar os aspectos de individualidade dos sujeitos que se desenvolvem em um tempo próprio. Assim, para que o tempo seja um elemento (re)significado pelos sujeitos sociais e que exista, por meio dele um "encontro" promissor com a informação, capaz de gerar o terreno para o desenvolvimento cultural, intelectual e da construção do conhecimento, conforme foi defendido por Gomes (2016), é relevante entender a busca e o estado de liberdade dos sujeitos 
sociais.

Os tempos são diferentes e, na relação com o mundo e com os outros, cada sujeito tem o seu que lhe é próprio. O tempo coletivo é assíncrono em relação aos tempos individuais. Em igual medida, o momento histórico determina formas de relação do indivíduo com o tempo assim como as relações com os dispositivos. Reconhecer essas diferenças é mister no processo de mediação, ao contrário, por exemplo, de imposições nas políticas educacionais, em que o tempo de ensino e o de aprendizado são os mesmos para todos, incluindo alunos e professores. No que diz respeito ao tempo, a apropriação acontece de maneira diferente de indivíduo para indivíduo e deve ser refletido tanto em relação aos usuários quanto aos mediadores.

O processo de mediação consciente da informação é evocado e necessário para garantir a apropriação da informação em consonância com o contexto sociocultural, em que as relações entre os sujeitos, os mediadores e os ambientes informacionais estão inseridos. Nesse sentido, defende-se que é preciso respeitar o tempo necessário para fortalecer as relações que favorecem o "encontro confortável" com a informação, sejam elas com o mediador, com o ambiente ou com o item informacional (no processo de leitura). Portanto, cada sujeito deve identificar e respeitar o tempo necessário para alcançar a efetividade da apropriação da informação. Assim, é preciso compreender os diferentes valores pragmático, afetivo e simbólico que permeiam o processo de mediação da informação e que estão refletidos e refletem as tessituras constitutivas das redes sociais.

\section{CONSIDERAÇÕES FINAIS}

O contexto social em que a produção e a disseminação das informações - algumas delas nem sempre confiáveis - integram um sistema de controle e de manipulação evoca sujeitos conscientes e humanizadores com o fim de garantir ao sujeito social o direito comum. Nesse contexto, tanto o mediador quanto $o$ usuário devem refletir sobre essa teia sociocultural e se portar, consciente e inteiramente, no processo de mediação e apropriação da informação. 
Os anseios e as necessidades dos usuários não são puros, porque os sujeitos estão imersos em uma estrutura social que impõe essas demandas. Assim, os mediadores e o ambiente informacionais devem atender a essas necessidades e refletir sobre elas de maneira crítica e consciente, para que essa percepção seja acionada também pelo usuário.

Pensamos no usuário como nosso grande norte, mas não podemos nos esquecer do mediador. É possível usar a mesma ideia presente na educação a de que quem ensina aprende - e adequá-la à mediação da informação: quem medeia também é mediado; quem medeia participa do processo de mediação, apropria-se de informações e tem seu conhecimento desestabilizado. $O$ mediador também é protagonista, no processo em que forma multiplicadores, cria meios, desenvolve métodos e constrói trajetórias para que outros sujeitos alcancem esse papel singular, que é o de protagonista social.

$\mathrm{Na}$ relação mediadora, o sujeito deve desenvolver, de maneira consciente, a percepção sensorial relacionada à escuta, à fala, ao gesto e ao olhar sensível do sujeito com seu meio. Esse desenvolvimento sensorial envolve a relação com o mediador, o dispositivo informacional e o usuário. Esses personagens alteram a mediação, tornam-na única e devem estar conscientes do processo de mediação da informação e entendê-la como uma interferência que demanda a percepção sensorial com um agir humanizador.

Diante do exposto, reiteramos que é preciso considerar o valor pragmático no processo de mediação da informação, em que os sujeitos respondem às demandas de seus múltiplos papéis sociais, buscam e podem passar a considerar os dispositivos informacionais como ambientes que respondem a esses anseios e que podem apresentar e construir uma trajetória de esclarecimentos sobre o que é imposto pelo sistema social, não Ihes proporcionando somente o acesso, mas também uma trajetória consciente da relação com a informação que poderá possibilitar sua apropriação. Assim, o mediador e o usuário poderão considerar e atribuir o valor pragmático ao processo de mediação da informação que responde, em um primeiro momento, as suas necessidades informacionais.

Ao mediar a informação e se apropriar dela, o mediador e os usuários 
poderão entender e fortalecer os laços entre eles e os dispositivos informacionais e desenvolver um sentimento de pertencimento, que poderá proporcionar a atribuição do valor afetivo ao processo de mediação da informação. Como seres sociais constituídos de emoções, os sujeitos devem ser considerados em seu todo, que envolve tanto a razão quanto o sentimento, que são indissociáveis. Assim, o valor afetivo deve ser considerado e alcançado por mediadores e usuários no processo de mediação da informação.

Os ambientes informacionais e os dispositivos que os integram são carregados de vestígios identitários de seus produtores e constituem os traços memorialísticos de indivíduos e grupos sociais, que perpassam o valor afetivo. A eles também é atribuído o valor simbólico. Para isso, os usuários devem se reconhecer nesses dispositivos informacionais, que, além de refletir os fatos, os acontecimentos e as histórias de contextos sociais e culturais de tempos remotos, devem estar abertos para o novo, para o cânone e para a expressão dos diversos sujeitos sociais e de suas comunidades que anseiam ser vistas e reconhecidas, não como uma produção menor, mas como a fala de um povo que, durante muito tempo, foi negligenciado. Assim, ao reconhecer as diferentes produções dos sujeitos que, durante muito tempo, tiveram sua fala negada $\mathrm{e}$ marginalizada, os ambientes informacionais por serem reconhecidos como plurais e inclusivos, podem atuar como dispositivos insurgentes ao sistema que padroniza e estigmatiza as diversidades que compõem a unidade. Portanto, por meio desse caminho, os mediadores e os usuários podem atribuir um valor simbólico ao processo de mediação da informação.

Nesse sentido, se a pluralidade e a unidade são respeitadas como constituintes dos meios socioculturais, que interferem no processo de mediação da informação, e se a emoção dos sujeitos é reconhecida, e suas múltiplas atuações sociais são fundamentadas por uma visão crítica e embasadas pelo acesso às fontes de informações confiáveis, o mediador da informação passa a ser um agente necessário e reconhecido, e tanto ele quanto os usuários passarão a entender o processo de mediação consciente da informação como uma convicção de agir no mundo. 


\section{REFERÊNCIAS}

ALMEIDA JÚNIOR, Oswaldo Francisco de. Mediação da informação: um conceito atualizado. In: BORTOLIN, S.; SANTOS NETO, J. A.; SILVA, R. J. (org.). Mediação oral da informação e da leitura. Londrina: Abecin, 2015. p. 9-32.

BRETON, Philippe. A manipulação da palavra. São Paulo: Loyola, 1999.

GOMES, Henriette Ferreira. Comunicação e informação: relações dúbias, complexas e intrínsecas. In: MORIGI, Valdir; JACKS, Nilda; GOLIN, Cida. (org.). Epistemologias, comunicação e informação. Porto Alegre: Sulina, 2016. p. 91-107.

GOMES, Henriette Ferreira. Mediação da informação e protagonismo social: relações com vida ativa e ação comunicativa à luz de Hannah Arendt e Jürgen Habermas. In: GOMES, Henriette Ferreira; NOVO, Hildenise Ferreira (org.). Informação e protagonismo social. Salvador: EDUFBA, 2017. p. 27-44.

GOMES, Henriette Ferreira. A dimensão dialógica, estética, formativa e ética da mediação da informação. Informação \& Informação, Londrina, v. 19, n. 2, p. 46-59, maio./ago. 2014. Disponível em:

http://www.uel.br/revistas/uel/index.php/informacao/article/view/19994. Acesso em: 26 mar. 2020.

GOMES, Henriette Ferreira. Protagonismo social e mediação da informação. Logeion: Filosofia da Informação, Rio de Janeiro, v. 5, n. 2, 2019. Disponível em: http://revista.ibict.br/fiinf/article/view/4644/4048. Acesso em: 13 abr. 2020.

GIL, Antônio Carlos. Como elaborar projetos de pesquisa. 5.ed. São Paulo: Atlas.2010.

OLIVEIRA, Amanda Leal de. A negociação cultural: um novo paradigma para a mediação e a apropriação da cultura escrita. 2014. Tese (Doutorado em Ciência da Informação) - Escola de Comunicações e Artes, Universidade de São Paulo, São Paulo, 2014.

PIERUCCINI, Ivete. Ordem informacional dialógica: mediação como apropriação da informação. In: ENCONTRO NACIONAL DE PESQUISA EM CIÊNCIA DA INFORMAÇÃO, 8., 2007, Salvador. Anais eletrônicos [...]. Salvador: Universidade Federal da Bahia, 2007. Disponível em: http://enancib.ibict.br/index.php/enancib/viiienancib/schedConf/presentations. Acesso em: 26 mar. 2020.

POLLAK, Michael. Memória e identidade social. Estudos Históricos, Rio de Janeiro, v. 5, n. 10, 1992. 


\title{
THE PRAGMATIC, AFFECTIVE AND SYMBOLIC VALUES IN THE PROCESS OF CONSCIOUS MEDIATION OF INFORMATION
}

\begin{abstract}
Introduction: The process of conscious mediation of information is evoked and necessary to ensure the appropriation of information in line with the socio-cultural context in which the relationships between subjects, mediators and information environments are inserted. In this context, it is necessary to understand the different values - pragmatic, affective and symbolic - that permeate the process of mediation of information, which are reflected and reflect the constitutive structure of social webs. Objective: To discuss, based on the theoretical foundation of information mediation, about the pragmatic, affective and symbolic values that permeate the process of conscious mediation and make it humanizing. Methodology: This is a descriptive research, of qualitative nature. With regard to procedures, it is characterized as bibliographic. Results: When users and the mediator understand the mediating action of the last agent as a concept of life, favors the development of a conviction of the relevance and social responsibility of its actions. Conclusions: The research proposes that, in the process of conscious mediation of information, the pragmatic, affective and symbolic values are attributed to the mediating action both by users and by the mediator himself, which relates it to a humanized performance and favors the development of a conviction the relevance and social responsibility of its actions.
\end{abstract}

Descriptors: Mediation of information. Pragmatic value - Mediation of information. Affective value - Mediation of information. Symbolic value - Mediation of information.

\section{LOS VALORES PRAGMÁTICOS, AFECTIVOS Y SIMBÓLICOS EN EL PROCESO DE MEDIACIÓN CONSCIENTE DE INFORMACIÓN}

\begin{abstract}
RESUMEN
Introducción: el proceso de mediación consciente de la información es evocado y necesario para garantizar la apropiación de la información, de acuerdo con el contexto sociocultural dónde están inseridas las relaciones entre los sujetos, mediadores y entornos informativos. En este contexto, es necesario comprender los diferentes valores - pragmáticos, afectivos y simbólicos - que impregnan el proceso de mediación de la información, que están reflejados y a su vez reflejan el tejido constitutivo de las redes sociales. Objetivo: Discutir, con base en los fundamentos teóricos de la mediación de información, sobre los valores pragmáticos, afectivos y simbólicos que impregnan el proceso consciente de mediación, tornándolo un proceso humanizador. Metodología: Esta es una investigación descriptiva, cualitativa. En cuanto a los procedimientos, se caracteriza por ser bibliográfica. Resultados: cuando los usuarios y el mediador entienden la acción mediadora de este último agente como un concepto de vida, favorecen el desarrollo de una convicción en cuanto a la relevancia y responsabilidad social de sus acciones. Conclusiones: La investigación propone que, en el proceso de mediación consciente de la información, los valores pragmáticos, afectivos y simbólicos
\end{abstract}


se atribuyen a la acción mediadora tanto por parte de los usuarios como del mediador, relacionándola con una actuación humanizadora, que favorece el desarrollo de una convicción de relevancia y responsabilidad social de sus acciones.

Descriptores: Mediación de la información. Valor pragmático - Mediación de la información. Valor afectivo - Mediación de la información. Valor simbólico - Mediación de la información.

Recebido em: 08.07.2020

Aceito em: 05.02.2021 